\title{
Study of dependence of magnetic properties on seeding temperature in fine particles of $\mathrm{Cu}_{0.25} \mathrm{Co}_{0.25} \mathrm{Zn}_{0.5} \mathrm{Fe}_{2} \mathrm{O}_{4}$
}

\author{
HINA BHARGAVA, V D SUDHEESH, SNEHAL JANI, N LAKSHMI* and K VENUGOPALAN \\ Department of Physics, Mohanlal Sukhadia University, Udaipur 313 001, India
}

MS received 4 October 2010; revised 1 March 2011

\begin{abstract}
Using a combination of X-ray diffraction, room temperature/low temperature Mössbauer studies and d.c. magnetization, the structural and magnetic properties of nano-sized $\mathrm{Cu}_{0.25} \mathrm{Co}_{0.25} \mathrm{Zn}_{0.5} \mathrm{Fe}_{2} \mathrm{O}_{4}$, prepared using the coprecipitation method at different seeding temperatures, have been studied. Formation of $\alpha-\mathrm{Fe}_{2} \mathrm{O}_{3}$ in these samples is observed to be very sensitive to the seeding temperature and is totally suppressed at a seeding temperature of $333 \mathrm{~K}$. These results are explained in terms of the rate of coprecipitation of the different components as a function of temperature. Since $\alpha-\mathrm{Fe}_{2} \mathrm{O}_{3}$ is antiferromagnetic, the presence and quantity of this impurity is also observed to deteriorate the overall magnetic properties of the spinel phase.
\end{abstract}

Keywords. Coprecipitation; seeding temperature; magnetic properties; Mössbauer spectroscopy.

\section{Introduction}

The chemical coprecipitation method has become popular in recent years for the preparation of both bulk and nano-sized ferrite materials (Rath et al 1999; Shi et al 1999; Upadhyay et al 2004; Arulmurugan et al 2005). This cheap and versatile technique allows the preparation of ferrites with good chemical homogeneity, control on the shape and size distribution of the synthesized particles (Rath et al 1999; Kim et al 2003; Arulmurugan et al 2005). The chemical coprecipitation method also allows the redistribution of different cations by varying the $\mathrm{pH}$ value and the initial seeding temperature, leading to vastly different structural and magnetic properties in ferrites of the same composition (Upadhyay et al 2001).

The mixed spinel, $\mathrm{Co}_{0.5} \mathrm{Zn}_{0.5} \mathrm{Fe}_{2} \mathrm{O}_{4}$, is well suited for the study of effect of initial preparation conditions on the cation distribution and substitution effects since Co has a strong preference for octahedral sites and $\mathrm{Zn}$ a strong preference for the tetrahedral sites (Vasambekarn et al 1999; Chinnasamy et al 2001). Recently, we had reported the magnetic properties of bulk and nano-sized $\mathrm{Cr}_{x} \mathrm{Co}_{0.5-x} \mathrm{Zn}_{0.5} \mathrm{Fe}_{2} \mathrm{O}_{4}$ and $\mathrm{Ni}_{x} \mathrm{Co}_{0.5-x} \mathrm{Zn}_{0.5} \mathrm{Fe}_{2} \mathrm{O}_{4}$ systems prepared by the chemical coprecipitation method and studied using Mössbauer effect (Sharma et al 2005a,b, 2006). However, in these studies, formation of a small percentage of $\alpha-\mathrm{Fe}_{2} \mathrm{O}_{3}$ was observed, which is undesirable from the application point-of-view. While Rath et al (1999) report a minimization of this component by adjustment of the $\mathrm{pH}$ value, there have not been many systematic studies on the effect of the seeding temperature, i.e. the temperature at which the solutions are main-

*Author for correspondence (nambakkat@yahoo.com) tained during the precipitation stage of preparation, on the $\alpha-\mathrm{Fe}_{2} \mathrm{O}_{3}$ content and on the magnetic and structural properties. This study reports the effect of seeding temperature on the structural and magnetic properties of nano-sized $\mathrm{Cu}$ substituted $\mathrm{Co}-\mathrm{Zn}$ ferrites prepared through the coprecipitation method keeping all initial parameters, except the seeding temperature, the same.

\section{Experimental}

Three sets of nano-sized ferrites of identical stoichiometry corresponding to $\mathrm{Cu}_{0.25} \mathrm{Co}_{0.25} \mathrm{Zn}_{0.5} \mathrm{Fe}_{2} \mathrm{O}_{4}$ were prepared by the chemical coprecipitation method at three different temperatures $(300 \mathrm{~K}, 333 \mathrm{~K}$ and $353 \mathrm{~K})$ in the initial seeding stage. This temperature is referred to as seeding temperature in this paper. A.R. grade $\mathrm{CuCl}_{2} \cdot 2 \mathrm{H}_{2} \mathrm{O}, \mathrm{CoCl}_{2} \cdot 6 \mathrm{H}_{2} \mathrm{O}, \mathrm{ZnCl}_{2}$, and $\mathrm{Fe}\left(\mathrm{NO}_{3}\right)_{3} \cdot 2 \mathrm{H}_{2} \mathrm{O}$ were weighed in stoichiometric ratios, mixed in an agate mortar and pestle and then dissolved in water maintained at temperature $300 \mathrm{~K}, 333 \mathrm{~K}$ and $353 \mathrm{~K}$. In the rest of this paper, samples prepared with seeding temperatures $300 \mathrm{~K}, 333 \mathrm{~K}$ and $353 \mathrm{~K}$, will be referred to as $\mathrm{S} 1, \mathrm{~S} 2$ and $\mathrm{S} 3$, respectively. $25 \%$ solution of $\mathrm{NH}_{4} \mathrm{OH}$ was added to the prepared solution to maintain a $\mathrm{pH}$ value of 10 . The solution was continuously stirred, maintaining a constant temperature (i.e. seeding temperature), till the precipitation was complete. The precipitate was then washed with water until $\mathrm{pH}$ value of rinsed water became 7 and dried at $373 \mathrm{~K}$ for $24 \mathrm{~h}$. Nano-sized samples were prepared by annealing at $573 \mathrm{~K}$ for $24 \mathrm{~h}$.

Structural characterization and determination of the average sizes of nano-sized samples were done using X-ray diffraction (XRD) spectra obtained on a Rigaku-Miniflex 


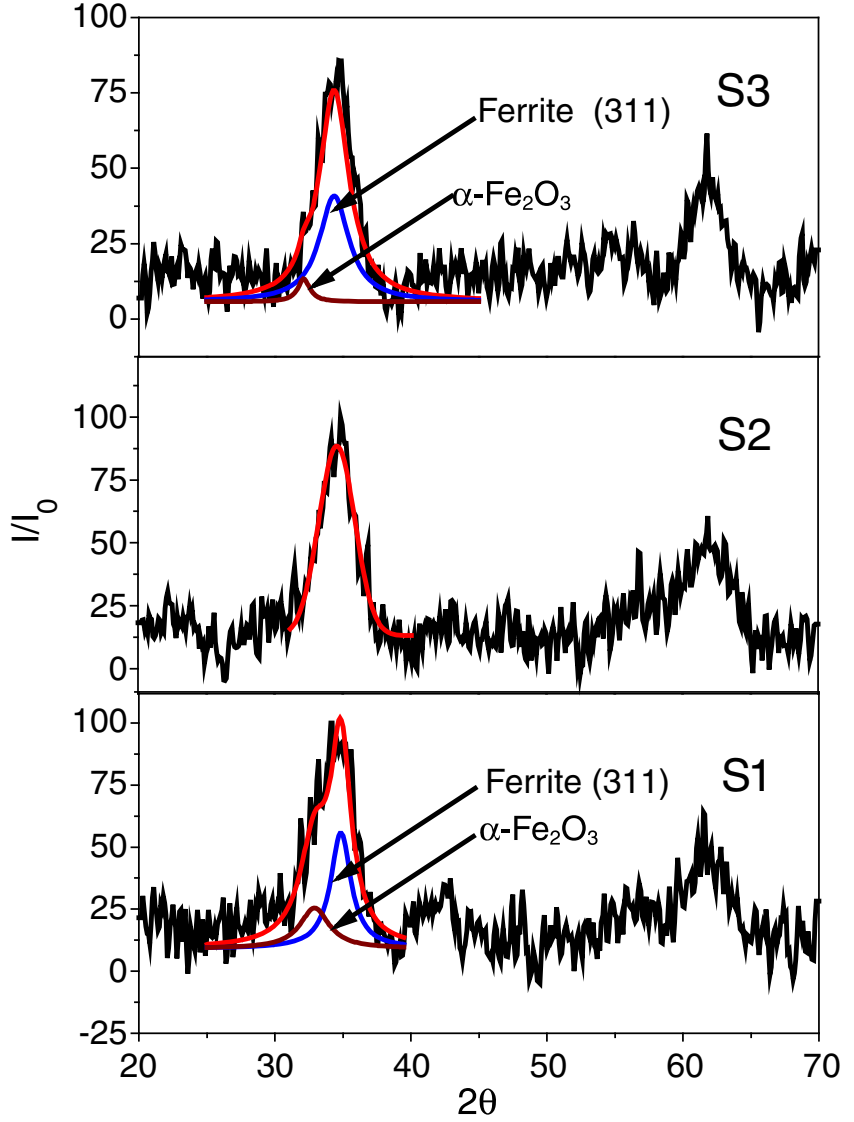

Figure 1. X-ray diffraction patterns for samples S1, S2 and S3.

$\mathrm{X}$-ray diffractometer with $\mathrm{Cu}-\mathrm{K} \alpha$ radiation. Mössbauer spectra were recorded using a standard Austin drive and controller assembly, in constant acceleration mode. The Mössbauer source used was a $12 \mathrm{mCi}{ }^{57} \mathrm{Co}$ in Rhodium matrix and velocity calibration was done using metallic iron foil. Magnetic measurements were done using a 7300 vibrating sample magnetometer (VSM). The blocking temperatures $\left(T_{\mathrm{B}}\right)$ of nano-sized samples were determined by plotting $M$ vs $T, M$ being the magnetic moment and $T$ the temperature from the zero field cooled (ZFC) curves over a temperature range of 50-300 K. A small d.c. field of 50 Oe was used for ZFC measurements.

\section{Results and discussion}

\subsection{XRD analysis}

Figure 1 shows the X-ray diffraction patterns of the samples S1, S2 and S3 prepared by coprecipitation method at different seeding temperatures (300 K (S1), $333 \mathrm{~K}$ (S2) and $353 \mathrm{~K}(\mathrm{~S} 3))$. The most intense peak in the X-ray diffraction patterns of samples $\mathrm{S} 1$ and $\mathrm{S} 3$ can be fitted with two Gaussian curves, advocate the co-existence of $\alpha-\mathrm{Fe}_{2} \mathrm{O}_{3}$ as impurity along with the spinel phase while that for sample S2 can be fitted with only single Gaussian curve, confirming the formation of single phased cubic spinel structure. Calculations show that $6.5 \pm 0.1 \%$ and $1.2 \pm 0.1 \%$ of $\alpha-\mathrm{Fe}_{2} \mathrm{O}_{3}$ is present in samples $\mathrm{S} 1$ and $\mathrm{S} 3$, respectively.

The reason for different amounts of $\alpha-\mathrm{Fe}_{2} \mathrm{O}_{3}$ present in the samples prepared identically except for a difference in the seeding temperature is that the rate of precipitation of all the components present is not the same (Rath et al 1999; Duan and Gregory 2003). At $300 \mathrm{~K}$, all the components do not coprecipitate as the precipitation rates are different for $\mathrm{Cu}$, $\mathrm{Co}, \mathrm{Zn}$ and $\mathrm{Fe}$ and this leads to the formation of $\alpha-\mathrm{Fe}_{2} \mathrm{O}_{3}$ in large quantity $(6.5 \%)$. For sample $\mathrm{S} 3$ the reaction rate becomes too fast because of the high seeding temperature $(353 \mathrm{~K})$ so that there is no time for complete digestion for the formation of hydroxide which leads to the formation of spinel ferrite resulting in the formation of $\alpha-\mathrm{Fe}_{2} \mathrm{O}_{3}$ in S3. The total absence of $\alpha-\mathrm{Fe}_{2} \mathrm{O}_{3}$ in sample S2 (seeding at $333 \mathrm{~K}$ ) indicates that at $333 \mathrm{~K}$ seeding temperature in this sample, complete digestion and coprecipitation of the component hydroxides is facilitated which subsequently gives rise to a pure spinel phase.

The average particle sizes of the spinel phase and of $\alpha$ $\mathrm{Fe}_{2} \mathrm{O}_{3}$ have been estimated from the broadening of XRD peaks using the Scherrer equation after correction for instrumental broadening and are shown in table 1. From figure 2, which correlates the average particle size with $\alpha-\mathrm{Fe}_{2} \mathrm{O}_{3}$ content, it is evident that presence of $\alpha-\mathrm{Fe}_{2} \mathrm{O}_{3}$ favours growth of the particle. Formation of $\alpha-\mathrm{Fe}_{2} \mathrm{O}_{3}$ is an exothermic reaction $(\Delta H=-824 \cdot 2 \mathrm{~kJ})$ and so on, the released energy supports the grain growth of ferrite particles and particle size increases as compared to the sample without any presence of $\alpha-\mathrm{Fe}_{2} \mathrm{O}_{3}$ (S2). The percentage porosity of the samples (table 1 ) have been calculated using the relation (Cullity 1978)

$$
p=\left(1-\left(\frac{d_{\text {mea }}}{d_{\text {cal }}}\right)\right) \times 100,
$$

where $d_{\text {mea }}$ is the measured density and $d_{\text {cal }}$ the X-ray density. Cullity and Graham (2009) pointed out that the variation in experimental densities and hence porosities in ferrites are intimately related to grain size. An increase in grain size leads to denser material with an accompanying decrease in porosity; i.e. there is a better match between X-ray and experimental densities. Another reason for this difference in densities is due to the presence of defects like oxygen or metal-ion vacancies in the lattice. In the present series, samples $\mathrm{S} 1$ and $\mathrm{S} 3$ in addition to being nano-sized also have $\alpha-\mathrm{Fe}_{2} \mathrm{O}_{3}$ as impurity, producing vacant sites in the crystal lattice of ferrite structure (Cullity and Graham 2009). This results in samples $\mathrm{S} 1$ and $\mathrm{S} 3$ having much larger porosities than sample S2.

\subsection{Mössbauer analysis}

Mössbauer spectroscopy is a powerful technique to characterize magnetic nanoparticles undergoing superparamagnetic relaxation. For extremely small particles with 
Table 1. Structural parameters for samples prepared at different seeding temperatures.

\begin{tabular}{|c|c|c|c|c|c|c|c|}
\hline Sample & $\begin{array}{c}\text { Lattice } \\
\text { constant }(\AA)\end{array}$ & $\begin{array}{c}\text { Particle } \\
\text { size } \pm 1(\mathrm{~nm})\end{array}$ & $\% \alpha-\mathrm{Fe}_{2} \mathrm{O}_{3}$ & $\begin{array}{c}\text { Particle size of } \\
\alpha-\mathrm{Fe}_{2} \mathrm{O}_{3} \pm 1(\mathrm{~nm})\end{array}$ & $\begin{array}{c}\text { X-ray } \\
\text { density }\left(\mathrm{g} / \mathrm{cm}^{3}\right)\end{array}$ & $\begin{array}{c}\text { Measured } \\
\text { density }\left(\mathrm{g} / \mathrm{cm}^{3}\right)\end{array}$ & Porosity \\
\hline S1 & $8 \cdot 381$ & 5 & $6 \cdot 5$ & 8 & $5 \cdot 39$ & $3 \cdot 19$ & 41 \\
\hline $\mathrm{S} 2$ & $8 \cdot 527$ & 3 & - & - & $5 \cdot 12$ & 3.68 & 28 \\
\hline S3 & 8.607 & 4 & $1 \cdot 2$ & 3 & 4.98 & $3 \cdot 17$ & 36 \\
\hline
\end{tabular}

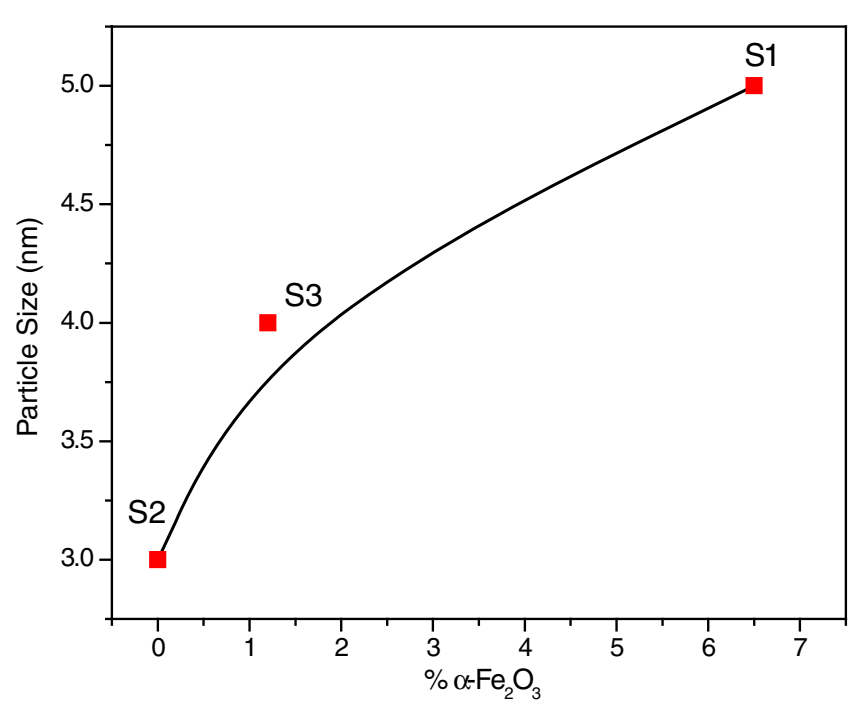

Figure 2. Dependence of particle size on amount of $\alpha-\mathrm{Fe}_{2} \mathrm{O}_{3}$.

uniaxial anisotropy, the energy barrier, which separates the two easy directions of magnetization, may be smaller than the thermal energy even at room temperature. This leads to the spontaneous fluctuation of the magnetization direction having relaxation time given by (Bhargava et al 2008)

$$
\tau=\tau_{0} \exp \left(\frac{K V}{k_{B} T}\right),
$$

where $\tau_{0}\left(10^{-9}-10^{-10} \mathrm{~s}\right)$ is the inverse of the natural frequency of the gyromagnetic precession, $K$ the anisotropy constant, $V$ the volume of particle, $k_{\mathrm{B}}$ the Boltzmann constant and $T$ the temperature (in Kelvin).

The superparamagnetic relaxation of the single domain magnetic nanoparticle may be observed by a technique with characteristic time $\left(\tau_{\mathrm{s}}\right)$ at the temperature above the so called blocking temperature $\left(T_{\mathrm{B}}\right)$ defined by

$$
T_{\mathrm{B}}=\frac{K V}{k_{\mathrm{B}} \ln \left(\frac{\tau_{\mathrm{s}}}{\tau_{0}}\right)} .
$$

Above the blocking temperature, the relaxation time $\tau<<\tau_{\mathrm{s}}$ ( $\sim 10^{-8} \mathrm{~s}$ for the Mössbauer spectroscopy) and the internal magnetic field is averaged out giving rise to usually a quadrupolar doublet in the Mössbauer pattern. Below the blocking temperature, $\tau>>\tau_{\mathrm{s}}$, a characteristic sextet

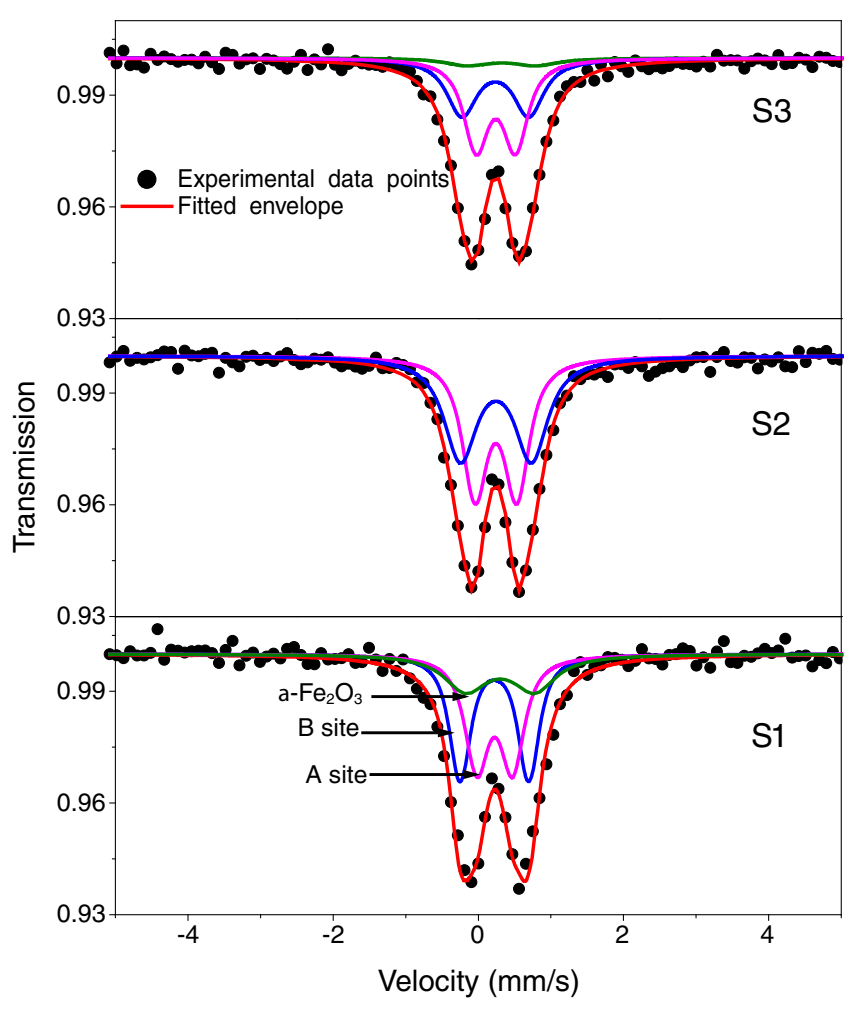

Figure 3. $R T$ Mössbauer spectrum of samples $\mathrm{S} 1, \mathrm{~S} 2$ and $\mathrm{S} 3$.

Mössbauer pattern is observed. Near the $\tau \sim \tau_{\mathrm{s}}$, a partially collapsed sextet with broad line is seen (Srivastava et al 1976).

Figure 3 shows the Mössbauer spectra taken at room temperature $(R T)$ for nano-sized $\mathrm{Cu}_{0.25} \mathrm{Co}_{0.25} \mathrm{Zn}_{0.5} \mathrm{Fe}_{2} \mathrm{O}_{4}$ prepared at different seeding temperatures (S1, S2 and S3). The presence of doublet alone in $R T$ Mössbauer spectra for these samples reveals the collapse of the magnetic ordering due to superparamagnetic relaxation. Mössbauer spectrum of sample S2 was fitted with two doublets corresponding to $A$ and $B$ sites whereas Mössbauer spectra of samples S1 and S3 were fitted with three doublets, corresponding to $A$ site, $B$ site and $\alpha-\mathrm{Fe}_{2} \mathrm{O}_{3}$. Results are shown in table 2 .

The isomer shift values obtained are characteristic of $\mathrm{Fe}^{3+}$ state. We note that the average isomer shifts of samples $\mathrm{S} 1$, S2 and S3 appear to show no significant change with seeding temperature, thus indicating that the $s$ electron charge distribution of $\mathrm{Fe}^{3+}$ ions is negligibly influenced by seeding temperature. The average quadrupole splitting (QS) of 
Table 2. Parameters obtained from fitting Mössbauer spectra of $\mathrm{Cu}_{0.25} \mathrm{Co}_{0.25} \mathrm{Zn}_{0.5} \mathrm{Fe}_{2} \mathrm{O}_{4}$ prepared at different seeding temperatures. Isomer shifts (IS) are quoted with respect to $\alpha$-Fe.

\begin{tabular}{|c|c|c|c|c|c|c|c|c|c|}
\hline \multirow[b]{2}{*}{ Sample } & \multicolumn{3}{|c|}{ Isomer shift $\pm 0 \cdot 047(\mathrm{~mm} / \mathrm{s})$} & \multicolumn{3}{|c|}{ Quadrupole splitting $\pm 0 \cdot 047(\mathrm{~mm} / \mathrm{s})$} & \multicolumn{3}{|c|}{ Width $\pm 0 \cdot 047(\mathrm{~mm} / \mathrm{s})$} \\
\hline & $A$-site & $B$-site & $\alpha-\mathrm{Fe}_{2} \mathrm{O}_{3}$ & $A$-site & $B$-site & $\alpha-\mathrm{Fe}_{2} \mathrm{O}_{3}$ & $A$-site & $B$-site & $\alpha-\mathrm{Fe}_{2} \mathrm{O}_{3}$ \\
\hline S1 & $0 \cdot 22$ & $0 \cdot 22$ & $0 \cdot 30$ & 0.49 & 0.94 & 0.95 & $0 \cdot 35$ & $0 \cdot 30$ & $0 \cdot 70$ \\
\hline $\mathrm{S} 2$ & $0 \cdot 24$ & $0 \cdot 24$ & - & 0.57 & 0.97 & - & $0 \cdot 38$ & 0.50 & - \\
\hline S3 & $0 \cdot 21$ & $0 \cdot 21$ & $0 \cdot 34$ & 0.74 & 0.99 & $0 \cdot 90$ & 0.55 & $0 \cdot 60$ & 0.75 \\
\hline
\end{tabular}

Table 3. Parameters obtained from fitting Mössbauer spectra of $\mathrm{Cu}_{0.25} \mathrm{Co}_{0.25} \mathrm{Zn}_{0.5} \mathrm{Fe}_{2} \mathrm{O}_{4}$ prepared at $333 \mathrm{~K}$ (S2). Isomer shifts (IS) are quoted with respect to $\alpha$-Fe.

\begin{tabular}{lcccc}
\hline Site & $\begin{array}{c}\text { Isomer shift } \\
\pm 0.047(\mathrm{~mm} / \mathrm{s})\end{array}$ & $\begin{array}{c}\text { Hyperfine field } \\
\pm 0.029(\mathrm{~T})\end{array}$ & $\begin{array}{c}\text { Width } \\
\pm 0.047(\mathrm{~mm} / \mathrm{s})\end{array}$ & $\begin{array}{c}\text { Cation } \\
\text { distribution }\end{array}$ \\
\hline$A$ & $0 \cdot 29$ & 45.5 & 0.56 & $\left(\mathrm{Zn}_{0.5} \mathrm{Fe}_{0.5}\right)^{A}\left[\mathrm{Cu}_{0.25} \mathrm{Co}_{0.25} \mathrm{Fe}_{1.5}\right]^{B}$ \\
$B 1$ & 0.31 & 50.8 & 0.45 & \\
$B 2$ & 0.28 & 48.5 & 0.60 & \\
$B 3$ & $0 \cdot 28$ & 41.5 & 0.73 & \\
\hline
\end{tabular}

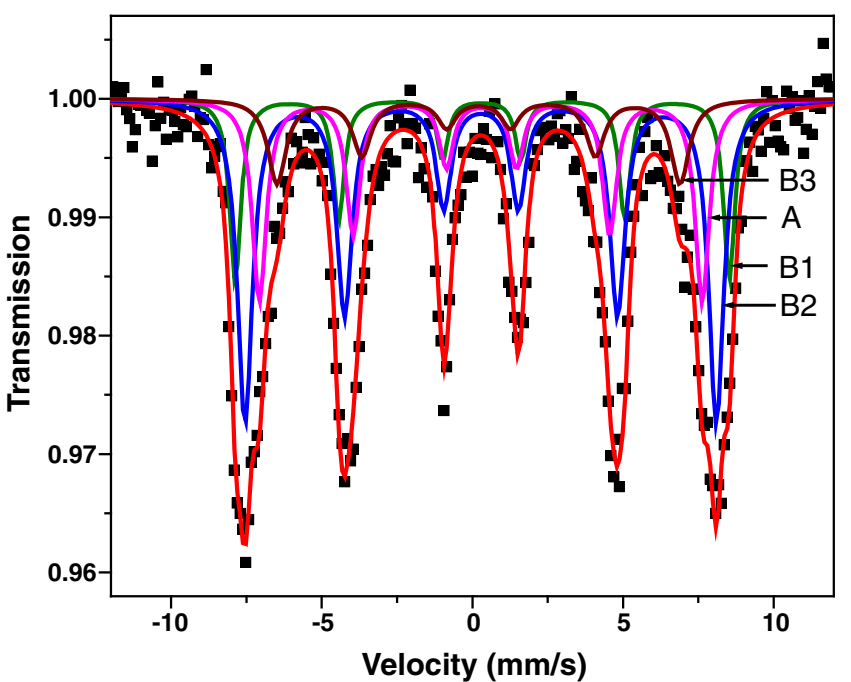

Figure 4. Mössbauer spectrum of sample S2 at $20 \mathrm{~K}$.

nano-sized samples is generally observed to be larger than that of the corresponding bulk material. For example, QS of $\mathrm{ZnFe}_{2} \mathrm{O}_{4}$ is $0.32 \mathrm{~mm} / \mathrm{s}$ in the bulk and $0.78 \mathrm{~mm} / \mathrm{s}$ in nano-sized particles, as reported by Daniels and Rosencwaig (1970). This indicates that there is difference in the structure between the nano-sized material and the bulk material. Large surface to volume ratio in nanoparticles and increase in the lattice constant is known to create large electric field gradients (EFG) in ferrites though the bulk materials have cubic symmetry (Wang and Li 2001). The linewidths obtained are, expectedly, very large for all samples (table 2) evidencing disorder due to lowered symmetries, broken bonds etc because of the large surface to volume ratio. This results in a wide distribution of the hyperfine fields around an average value (Chinnasamy et al 2001).

To confirm the superparamagnetic nature of prepared samples, low temperature Mössbauer of sample S2 (i.e. the sample consisting of a pure spinel phase) at $20 \mathrm{~K}$ has been taken (figure 4). Superparamagnetic relaxation is suppressed at $20 \mathrm{~K}$ and the Mössbauer of sample S2 consists of four sextets corresponding to one $A$ and three $B$ sites (marked B1, B2 and B3 in figure 4 ). The observed parameters for the sextets are listed in table 2 . The large linewidths and several $B$ sites are because of the presence of four different cations which are randomly distributed, leading to more than one site. In ferrites, the arrangement of cations at the $A$ site affects the hyperfine fields at the $B$ site and vice-versa because the magnetic interactions are of the superexchange type, mediated by oxygen ions. Although such a random distribution of cations can occur at both sites, the $B$ site is more affected by the difference that occurs in the cation distribution at the $A$ site. This is because the $B$ site has six $A$ sites as nearest neighbours (nn) while the $A$ site has $B$ sites as $n n$ and so the possibility of formation of more than one distinct $A$ site is $1 / 12$ th that of the $B$ site. The observed differences between the isomer shifts at $20 \mathrm{~K}$ and $R T$ are fully explained by the temperature dependent second order Doppler shift of the lines (tables 2 and 3). The cation distribution of this sample is given in table 3 .

\subsection{DC magnetization}

Figure 5 (a) shows reversible magnetization $(M-H)$ curves, corresponding to different seeding temperatures, with coercivity and remanent magnetization being zero, typical of superparamagnetic behaviour, which are not saturated with 

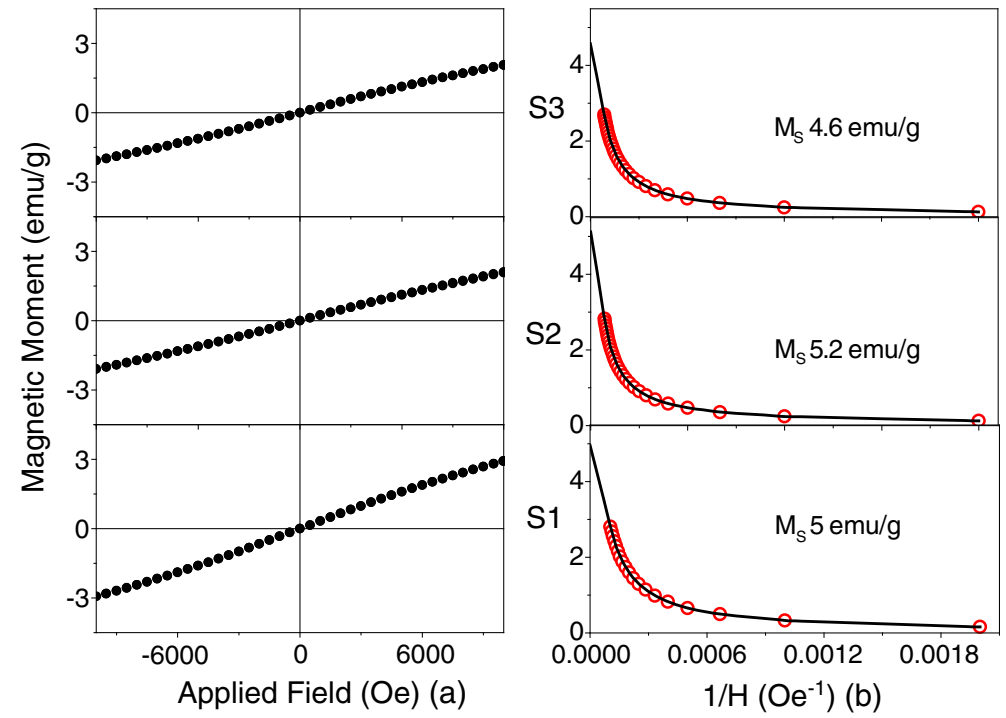

Figure 5. (a) $R T M-H$ loops of samples $\mathrm{S} 1, \mathrm{~S} 2$ and $\mathrm{S} 3$ and (b) magnetic moment vs $1 / H$ to estimate saturation magnetization.

Table 4. Obtained d.c. magnetization parameters (of the spinel phase) for samples prepared at different seeding temperatures.

\begin{tabular}{lccc}
\hline Sample & $\begin{array}{c}\text { Saturation } \\
\text { magnetization } \\
(\mathrm{emu} / \mathrm{g})\end{array}$ & $\begin{array}{c}\text { Blocking } \\
\text { temperature } \\
(\mathrm{K})\end{array}$ & $\begin{array}{c}\text { Anisotropy } \\
\text { constant } \\
\left(\mathrm{erg} / \mathrm{cm}^{3}\right)\end{array}$ \\
\hline S1 & $5 \cdot 0$ & 81 & $2 \cdot 49 \mathrm{E}+06$ \\
S2 & $5 \cdot 2$ & 61 & $1 \cdot 32 \mathrm{E}+07$ \\
S3 & $4 \cdot 6$ & 69 & $3 \cdot 97 \mathrm{E}+06$ \\
\hline
\end{tabular}

the available field of $1 T$. This is an indication of the presence of large anisotropy in the material. Saturation magnetization of the samples is estimated by plotting $M$ vs $1 / H$ for $1 / H$ tending to zero (figure $5(\mathrm{~b})$ ). The observed saturation magnetization of all samples is about $\sim 5 \mathrm{emu} / \mathrm{g}$, and is very small as compared to the bulk. This is because it is well established that in very fine magnetic particles, a large part of the spins are at the surface sometimes amounting to even $70 \%$ as was observed in nano-sized samples of $\mathrm{Ni}_{0.25} \mathrm{Co}_{0.25} \mathrm{Zn}_{0.5} \mathrm{Fe}_{2} \mathrm{O}_{4}$ (Lakshmi et al 2009) which were of nearly the same size and synthesized using the same method as the present samples. Due to vacancies, broken bonds and a general lowering of symmetry at the surface, these spins (at the surface) align such that the effective moment is zero. Thus the effective moment contribution from the sample is due to core spins alone resulting in a much lowered value than that in the corresponding bulk sample where surface effects are negligible. The blocking temperature, $T_{\mathrm{B}}$ (table 4), has been determined from the maxima obtained from ZFC curves (figure 6). It is seen that sample $\mathrm{S} 1$ has the highest $T_{\mathrm{B}}$ i.e. $81 \mathrm{~K}$, and the other two samples have smaller blocking temperatures. Moreover, a careful examination of ZFC curve

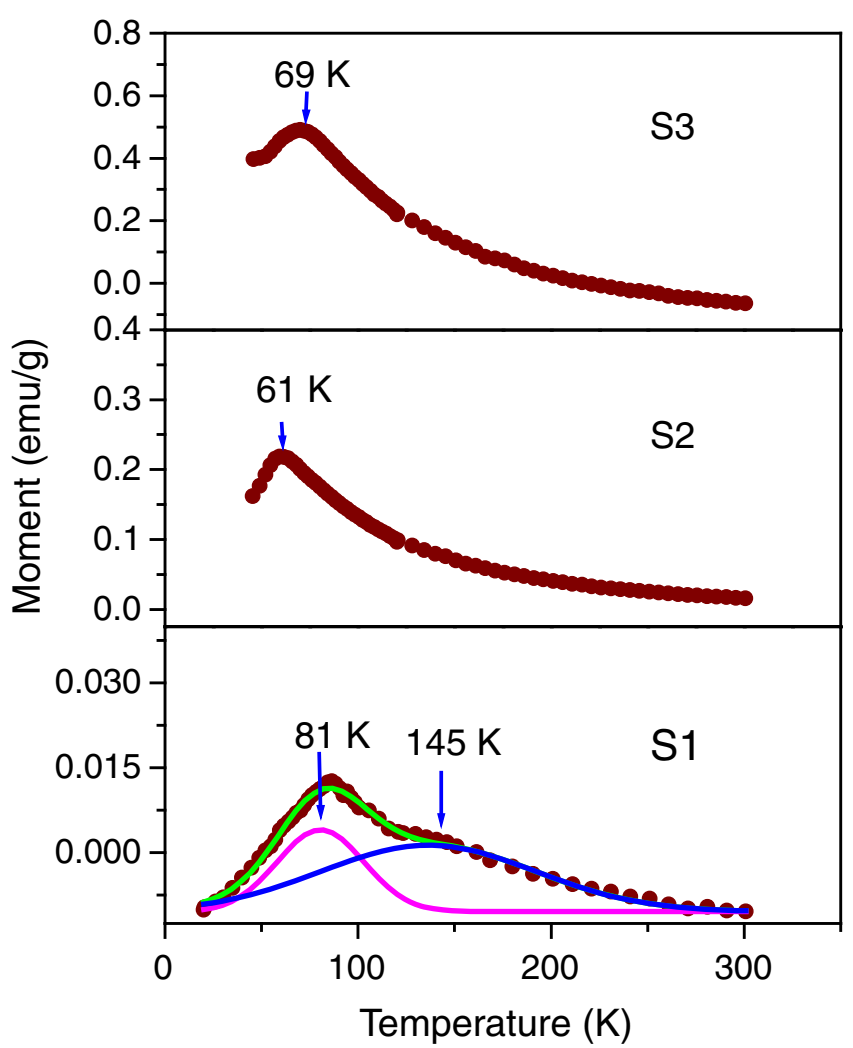

Figure 6. ZFC curves for samples S1, S2 and S3.

of sample S1 shows the presence of two components - one a main peak at $81 \mathrm{~K}$ and an additional shoulder at around $145 \mathrm{~K}$. The ZFC curve for this sample can be fitted with two broad Gaussian curves. In sample S1, the average size of 


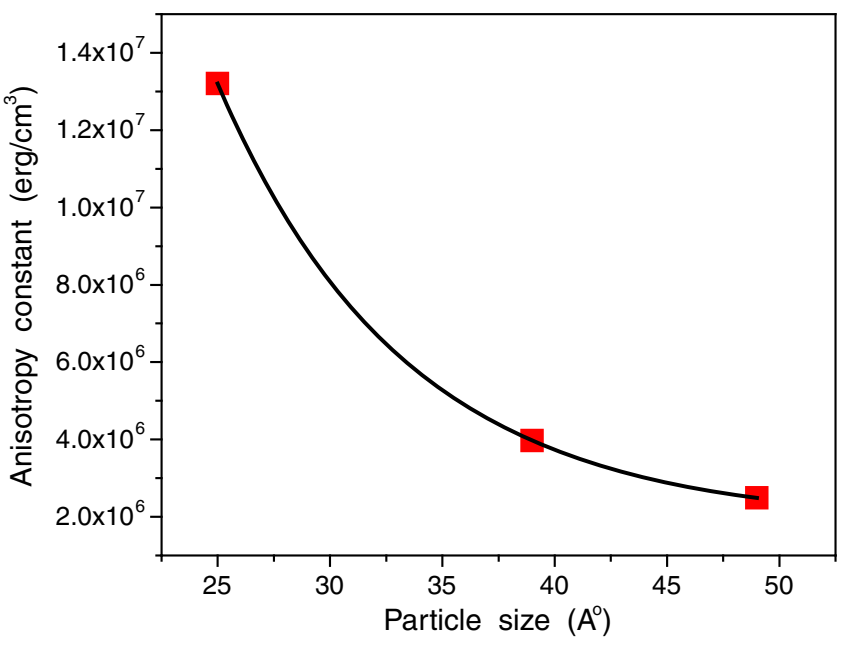

Figure 7. Exponential decrease in anisotropy constant with increase in particle size of nano-sized $\mathrm{Cu}_{0.25} \mathrm{Co}_{0.25} \mathrm{Zn}_{0.5} \mathrm{Fe}_{2} \mathrm{O}_{4}$.

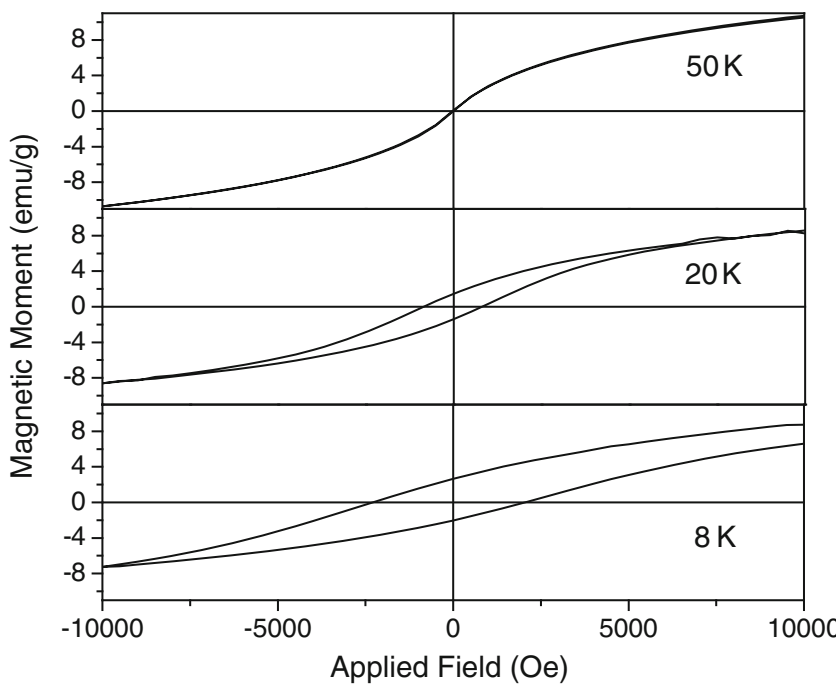

Figure 8. Low temperature $M-H$ loops of sample $\mathrm{S} 2$ taken at $8 \mathrm{~K}, 20 \mathrm{~K}$ and $50 \mathrm{~K}$.

$\alpha-\mathrm{Fe}_{2} \mathrm{O}_{3}$ at $\sim 8 \mathrm{~nm}$ is nearly 1.6 times larger than the $5 \mathrm{~nm}$ sized spinel phase. From the following equation

$$
T_{\mathrm{B}}=\frac{K V}{25 k_{\mathrm{B}}},
$$

where $K$ is the effective anisotropy constant, $V$ the volume and $k_{\mathrm{B}}$ the Boltzmann constant. It is evident that in nano-sized samples, in general, $T_{\mathrm{B}}$ is directly proportional to the volume, implying that larger sized particles will have larger $T_{\mathrm{B}}$. Thus the peak at $81 \mathrm{~K}$ can be attributed to the spinel phase and that at $145 \mathrm{~K}$ to $\alpha-\mathrm{Fe}_{2} \mathrm{O}_{3}$. The broad nature of the ZFC curve of sample $\mathrm{S} 1$ can be attributed to the large particle size distribution present in the sample (Kim et al 2003). Although the particle size is larger in samples S1 and S3 than S2, the estimated saturation magnetization of sample $\mathrm{S} 2$ is highest among prepared samples and reflects the amount of $\alpha-\mathrm{Fe}_{2} \mathrm{O}_{3}$ present in these samples. While the surface dead layer effect due to surface spins is the most prominent, the finer differences between the $M_{\mathrm{s}}$ between the samples is because the antiferromagnetic nature of $\alpha-\mathrm{Fe}_{2} \mathrm{O}_{3}$ suppresses the saturation magnetization. From the experimentally determined values of $T_{\mathrm{B}}$ and the particle sizes, the anisotropy energies for the nano-sized samples have been calculated using (4).

The calculated values of the anisotropy energy agree well with the range of reported values (Cullity 1972). Also, the anisotropy energy is seen to decrease exponentially with increase in particle size (figure 7). Low temperature $M-H$ curves have been recorded for sample $\mathrm{S} 2$ at $8 \mathrm{~K}, 20 \mathrm{~K}$ and $50 \mathrm{~K}$, which are well below the blocking temperature for this sample (figure 8). Presence of open loop at $8 \mathrm{~K}$ suggests field irreversibility (Kale et al 2004) and the presence of hysteresis at low temperature supports the predicted superparamagnetic nature of the prepared samples.

\section{Conclusions}

In conclusion, this study clearly establishes the sensitivity of a proper choice of initial conditions, particularly the seeding temperature while using the coprecipitation method for synthesis of spinel ferrites. The presence of even a small amount of $\alpha-\mathrm{Fe}_{2} \mathrm{O}_{3}$, clearly affects both, the structural and magnetic properties in these materials.

\section{Acknowledgements}

We acknowledge UGC-DSA and DST-FIST programs at the Physics Department, M.L. Sukhadia University, Udaipur. We also thank Prof. A Gupta and Dr V R Reddy, UGC-DAE CSR, Indore, for low temperature Mössbauer measurements. (VDS) thanks the UGC for a fellowship (SRF)

\section{References}

Arulmurugan R, Jeyadevan B, Vaidyanathan G and Sendilhnathan S 2005 J. Magn. Magn. Mater. 288470

Bhargava H, Lakshmi N, Sharma R K and Venugopalan K 2008 Hyperfine Interact. 183155

Chinnasamy C N, Narayanasamy A, Ponpandian N and Chattopadhyay K 2001 Mater. Sci. Eng. A304-306 983

Cullity B D 1972 Introduction to magnetic materials (Reading MA: Addison-Wesley) p. 234

Cullity B D 1978 Elements of X-ray diffraction (Reading, MA: Addison-Wesley Publishing Co.) 2nd ed.

Cullity B D and Graham C D 2009 Introduction to magnetic materials (Hoboken, New Jersey: John Wiley \& Sons. Inc.) p. 472

Daniels J M and Rosencwaig A 1970 Can. J. Phys. 48381 
Duan J and Gregory J 2003 Adv. Colloid. Interf. Sci. 100-102 475

Kale A, Gubbala S and Misra R D K 2004 J. Magn. Magn. Mater. 277350

Kim Y I, Kim D and Lee C S 2003 Phys. Rev. B337 42

Lakshmi N, Bhargava H, Suwalka O P, Venugopalan K, Sebastian V, Reddy V R and Gupta A 2009 Phys. Rev. B80 1

Rath C, Sahu K K, Anand S, Date S K, Mishra N C and Das R P 1999 J. Magn. Magn. Mater. 20277

Sharma R K, Suwalka O, Lakshmi N, Venugopalan K, Banerjee A and Joy P A 2005a Mater. Lett. 593402

Sharma R K, Suwalka O, Lakshmi N and Venugopalan K 2005b Hyperfine Interact. 165261
Sharma R K, Suwalka O, Lakshmi N and Venugopalan K 2006 Synth. React. Inorg., Met.-Org., Nano-Met. Chem. 36175

Shi Y, Ding J, Liu X and Wang J 1999 J. Magn. Magn. Mater. 205 249

Srivastava C M, Shringi S N and Srivastava R G 1976 Phys. Rev. B14 2041

Upadhyay C, Verma H C and Anand S 2004 J. Appl. Phys. 955746 Upadhyay C, Verma H C, Rath C, Sahu K K, Anand S, Das R P and Mishra N C 2001 J. Alloys Compd 32694

Vasambekar P N, Kolekar C B and Vaingankar A N 1999 Mater. Chem. Phys. 60282

Wang L and Li F S 2001 J. Magn. Magn. Mater. 223233 